\title{
Addendum
}

\section{Transition-Metal-Catalyzed Enantioselective Synthesis of Compounds with Non-Centrochirality}

\author{
Masamichi Ogasawara,* Susumu Watanabe Synthesis 2009, 1761.
}

After publication of the above review article, the authors became aware that the majority of research works on 'the catalytic asymmetric synthesis of planar-chiral chromium $(0)-\left(\eta^{6}\right.$-arene) complexes' were erroneously omitted. The sections 2.1 a-c given below should be added after the Section 2.1 in the review article. The authors apologize for the oversight.

2.1a Synthesis of Planar-Chiral Chromium(0)- $\left(\eta^{6}\right.$ arene) Complexes by Palladium-Catalyzed Methoxycarbonylation

Palladium-catalyzed methoxycarbonylation was applied to the preparation of planar-chiral chromium(0)-arene complexes by Schmaltz and co-workers. A palladium complex coordinated with $(R)-(S)$-ppf-pyrrolidine was effective in desymmetrizing $\mathbf{5}$, and the monoester $(1 S)$-A1 was obtained in $95 \%$ ee (31\% yield) together with $48 \%$ of the achiral diester A2 (Scheme A1). ${ }^{\text {Ala }}$ Although the ee value of the initially formed A1 was not so high (ca. 60\% ee), (1S)-A1 of higher optical purity could be obtained because the minor enantiomer $(1 R)$-A1 was consumed more rapidly than its antipode in the second methoxycarbonylation leading to $\mathbf{A 2}$.

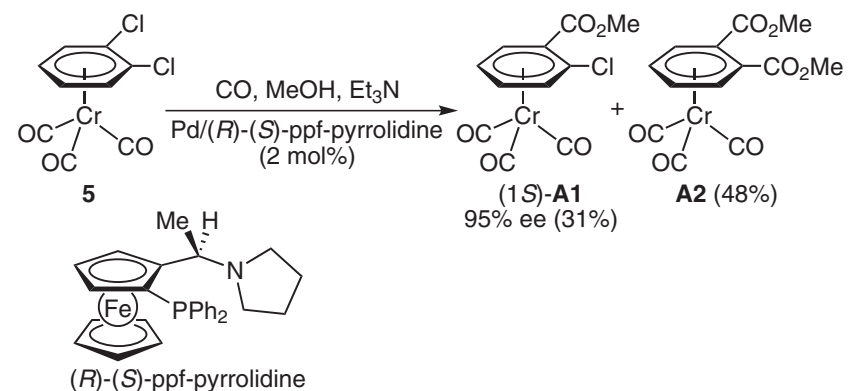

Scheme A1
The same catalytic system was also applied to the desymmetrization of the tricarbonyl $\left(\eta^{6}-1,3\right.$-dichloroarene) chromium(0) complexes A3. ${ }^{\mathrm{Alb}}$ A substituent at the 2-position in the $\eta^{6}$-arene moiety affected some enantioselectivity in the palladium-catalyzed reaction. Although the 2-unsubstituted substrate $\mathbf{A 3 a}$ gave a nearly racemic product, $\mathbf{A} \mathbf{4 b}$ and $\mathbf{A} 4 \mathbf{c}$ were obtained in 90 and $41 \%$ ee, respectively (Scheme A2). In the second methoxycarbonylation of A4b giving A5b, a kinetic resolution with a selectivity factor of $S=4.3$ was observed.

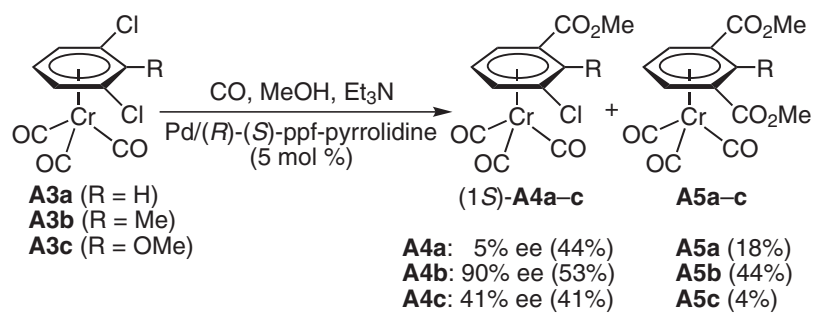

Scheme A2

2.1b Palladium-Catalyzed Intramolecular MizorokiHeck Reaction of Planar-Prochiral Chromium(0)- $\left(\eta^{6}-\right.$ arene) Complex

In 2005, Uemura described that a palladium complex coordinated with a phosphoramidite $(S)$-A9 gave rise to asymmetric intramolecular Mizoroki-Heck reactions of ( $\eta^{6}$-1,3-bisalkenyl-2-chlorobenzene)chromium $(0)$ complexes A6 with moderate enantioselectivity (Scheme A3). ${ }^{\text {A2 }}$ While the bis(3-butenyl) substrate A6a afforded the cyclized product $\mathbf{A 7 a}$ in $67 \%$ ee $\left(40{ }^{\circ} \mathrm{C}\right)$ and $73 \%$ ee $\left(60{ }^{\circ} \mathrm{C}\right)$, the bis(4-pentenyl) homologue $\mathbf{A} 7 \mathbf{b}$ provided A7b in lower enantioselectivity of $40 \%$ ee at $60{ }^{\circ} \mathrm{C}$.

A palladium intermediate, which was generated after the carbopalladation/cyclization step in the Mizoroki-Heck reaction, could be trapped with an aryl- or alkenylboronic acid nucleophile. The Mizoroki-Heck/Suzuki-Miyaura cascade process proceeded with excellent diastereoselectivity and A8 was obtained in 54\% yield from A6a as a single diastereomer, for which the enantiomeric excess was $68 \%$ ee. 

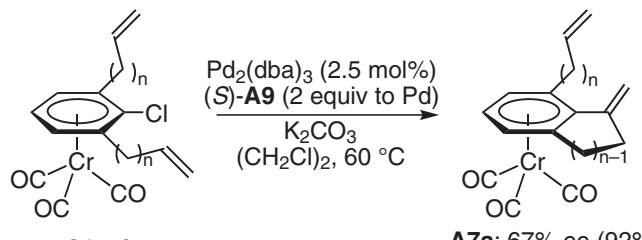

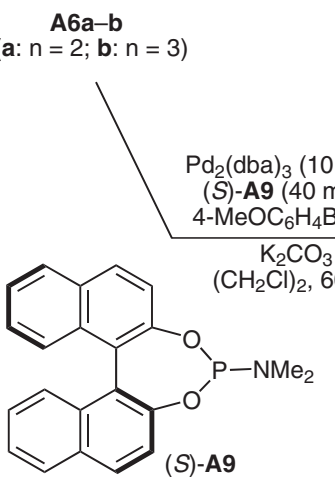

Scheme A3

2.1c Palladium-Catalyzed Enantioselective Hydrogenolysis of $\left(\eta^{6}-5,8\right.$-Dibromonaphthalene $) \operatorname{Cr}(\mathrm{CO})_{3}$

Enantioposition-selective hydrogenolysis of planarprochiral $\quad\left(\eta^{6}\right.$-5,8-dibromonaphthalene $) \mathrm{Cr}(\mathrm{CO})_{3} \quad$ (A10) was accomplished with excellent enantioselectivity by Kündig and co-workers in 2006. ${ }^{\mathrm{A} 3}$ A palladium complex coordinated with the bulky phosphoramidite $(S, R, R)$-A13 was found to be an excellent catalyst for the asymmetric reaction, and the planar-chiral ( $\eta^{6}$-arene)tricarbonylchromium $(0)(p R)$-A11 was obtained in $97 \%$ ee in $78 \%$ yield under the optimized conditions (Scheme A4).

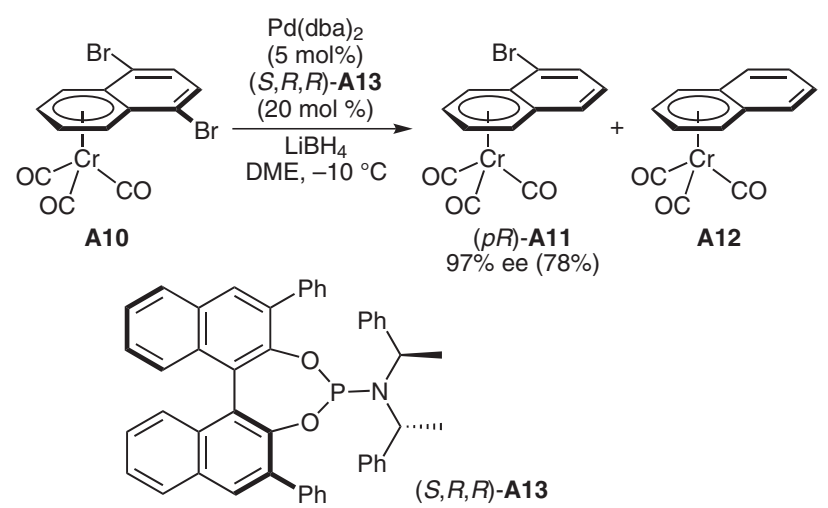

Scheme A4

\section{References}

(A1) (a) Gotov, B.; Schmalz, H.-G. Org. Lett. 2001, 3, 1753. (b) Böttcher, A.; Schmalz, H.-G. Synlett 2003, 1595.

(A2) Kamikawa, K.; Harada K.; Uemura, M. Tetrahedron: Asymmetry 2005, 16, 1419.

(A3) Kündig, E. P.; Chaudhuri, P. D.; House, D.; Bernardinelli, G. Angew. Chem. Int. Ed. 2006, 45, 1092. 